\title{
DESAFIANDO CRIANÇAS A PENSAR: INTERVENÇÃO COM JOGOS POR TRÊS SEMESTRES
}

\author{
Clarice Kunsch ${ }^{1}$ \\ Instituto de Psicologia da USP. \\ Maria Thereza C. C. de Souza ${ }^{2}$ \\ Instituto de Psicologia da USP. \\ Ana Lucia Petty ${ }^{3}$ \\ Instituto de Psicologia da USP.
}

\section{RESUMO}

Este estudo investigou o terceiro semestre de um programa de intervenções com jogos, visando analisar registros sobre procedimentos e atitudes de crianças do Fundamental I com dificuldades escolares. O método consistiu na análise de informações registradas em dois protocolos. Os resultados mostraram que: (1) houve estabilização em escores mais altos no jogar; (2) ocorreu disposição para avaliar o desempenho, mesmo nos casos em que oscilações ainda se manifestaram no contexto do jogo; (3) notou-se predomínio de escores de média e alta qualidade em tempo, o que favoreceu o enfrentamento das dificuldades em convivências, que também registrou escores mais altos; e (4) todos terminaram em diferentes níveis de reequilibração das estratégias de ação, com progressos e boas condições de receber alta. Concluindo, as atividades deste semestre ampliaram a tomada de consciência e permitiram estabilização dos procedimentos para jogar e das atitudes, favorecendo a autonomia e a superação das dificuldades anteriores.

Palavras-chave: intervenção; jogos; desenvolvimento infantil.

\footnotetext{
${ }^{1}$ Mestre em Psicologia Escolar e do Desenvolvimento Humano pelo Instituto de Psicologia da Universidade de São Paulo (IPUSP). Email: claricekkunsch@hotmail.com

2 Professora Titular da Universidade de São Paulo. Email: mtdesouza@usp.br

${ }^{3}$ Mestre em Psicologia Escolar e do Desenvolvimento Humano pelo IPUSP. Email: anapetty44@gmail.com
} 


\title{
CHALLENGING CHILDREN TO THINK: INTERVENTION WITH GAMES DURING THREE SEMESTERS
}

\begin{abstract}
This study investigated the third semester of an intervention program with games, aiming at analyzing records on procedures and attitudes of the elementary school children with learning difficulties. The method consisted of the analysis of information recorded in two protocols. Results showed: (1) stabilization at higher scores in the game context; (2) willingness to evaluate the play performance, even in the cases where oscillations still occurred; (3) predominance of medium and high-quality scores in time, which favored children to deal with difficulties in interactions, which also registered higher scores; and (4) children finalized the program at different levels of rebalancing, presenting progress and good conditions to be discharged. To conclude, the activities of this semester increased awareness and allowed stabilization of the playing procedures and attitudes, favoring autonomy, and overcoming previous difficulties.
\end{abstract}

Keywords: intervention; games; child development.

\section{Introdução}

Esta pesquisa deu continuidade a uma investigação que começou com a análise dos registros do primeiro e segundo semestres de um programa de intervenção com jogos realizado no contexto de um laboratório que atende crianças com dificuldades escolares (De Souza et al, 2018; Petty, Kunsch \& Souza, submetido).

O terceiro semestre de participação consecutiva nas oficinas de jogos tem como característica proporcionar a consolidação (reequilibração) da transição ocorrida nos semestres anteriores para um novo patamar de equilíbrio. Assim, as consequências do processo de intervenção se manifestaram, com estabilizações mais evidentes dos elementos transformados pela tomada de consciência e autorregulações. Deste modo, o que oscilou no primeiro semestre e mudou no segundo agora deve apresentar progresso, e o que já estava estável assim deverá permanecer. Isto significa que: (a) as crianças atingiriam o melhor possível que podiam expressar em termos da qualidade de jogar, principalmente no que se refere à disposição para avaliar; (b) quanto aos aspectos atitudinais, uma vez que havia muita diferença entre elas em termos do momento de desenvolvimento, se notoumovimento ascendente para um novo patamar de equilíbrio, dentro da possibilidade de cada uma; (c) nas dimensões tempo e convivências (com os outros e consigo mesmo) que se configuravam como sendo grandes desafios durante os semestres anteriores, foi possível constatar algumas mudanças importantes, as quais serão consideradas na discussão dos resultados.

\section{Fundamentação teórica}

A fundamentação teórica do programa de intervenção com oficinas de jogos se baseia na teoria de Jean Piaget quanto a seus princípios interacionistas e construtivistas, especialmenteos conceitos de tomada de consciência e equilibração. Estes foram apresentados pelo autor em suas últimas obras (na década de 1970) e focalizam essencialmente o funcionamento da inteligência 
em termos das relações entre as perturbações ao equilíbrio do sistema cognitivo, as regulações (reações às perturbações) e as compensações das mesmas. A busca pelo equilíbrio é o ponto central da perspectiva piagetiana do desenvolvimento mental, sendo que o modo (mais restrito ou mais amplo) como o sujeito reorganiza e constrói novas estratégias para enfrentar as perturbações revela o quanto progrediu na avaliação dos resultados de suas ações, conjuntamente com as relações entre os procedimentos e as estruturas mentais subjacentes. A tomada de consciência não é uma iluminação abrupta de algo que até o momento não tinha sido percebido; trata-se, ao contrário, de um processo ativo de reconstrução gradativa no plano da conceituação de algo que tinha sido construído no plano da ação prática. Esta relação entre o fazer (réussir em francês) e o compreender (comprendre) é central para observar o quanto e como o sujeito assimila novos elementos das situações às suas estruturas, acomodando-se (o que requer ajustes) a estes, em maior ou menor grau (Piaget, 1977 e 1978).

O jogo e as situações-problema dele advindas são a matéria-prima para a expressão das interações entre jogador, jogo e estratégias; entre sujeito e objeto de conhecimento. O jogo é uma "instituição infantil" (Piaget, 1994) que cativa o interesse de crianças de diferentes idades. Sua organização por meio de regras promove o contato com normatizações intrínsecas ao jogar, assim como à vida social. No que se refere às oficinas de jogos, diversos estudos demonstram sua pertinência para promover tanto a modificação de procedimentos como de atitudes (Macedo, Petty \& Passos, 1997, 2000, 2005; Macedo et al. 2014, 2015). Nestes, destacam-se o lúdico e a ação de jogar como meios de acesso ao dinamismo infantil e como mediação entre criança e conhecimento. Além disso, pesquisas já demonstraram o valor das intervenções com jogos e seu papel fundamental para favorecer a superação de dificuldades escolares (De Souza et al. 2002; De Souza et al. 2014; De Souza \& Petty, 2017; Petty \& De Souza, 2012, 2014). Somam-se a isto duas investigações realizadas com os participantes das oficinas de jogos para a produção de teses, que ressaltaram sua relevância para o desenvolvimento psicológico infantil (Folquitto, 2013; Garbarino, 2017).

As atividades de intervenção que ocorrem no contexto das oficinas de jogos se baseiam também nos conceitos de funções executivas (FE), tais como compreendidos pela Psicologia Cognitiva, ou seja, como habilidades relacionadas ao processamento cognitivo, essenciais para a resolução de tarefas e tomada de decisões. De acordo com Cypel (2007) e Diamond (2013), estas funções são fundamentais para o bom funcionamento cognitivo, interferindo também nas emoções e na adaptação social. O controle inibitório, a memória operacional ou de trabalho e a flexibilidade cognitiva, relacionados à autorregulação, interferem diretamente nos modos como os indivíduos resolvem problemas e se ajustam ao dia a dia.

Os desafios presentes nas intervenções com jogos demandam o uso das FE, pois exigem que: (1) a atenção esteja focada; (2) os procedimentos sejam "guardados" na memória para uso diante dos desafios; e (3) a flexibilidade cognitiva leve a sistemas produtores de estratégias, para que o processo de autorregulação ocorra de modo desejável. É possível observar relações entre as conceituações a respeito das FE e o conceito de equilibração postulado por Piaget (1974), enquanto o que explica a passagem de um patamar de menor equilíbrio, para outro, melhor. Isto significa considerar que, para resolver de modo bem-sucedido as situações-problema dos jogos, o sujeito deverá aplicar as FE com intencionalidade, o que lhe permitirá atingir novos patamares de equilíbrio. As habilidades executivas poderiam, então, auxiliar o funcionamento da inteligência em contextos específicos que exijam planejamento com tomada de decisões, sendo um dos elementos importantes do processo de conscientização das ações. É importante destacar que isso não se restringe ao contexto do jogar, já que o bom uso das FE contribui para as ações infantis nos mais diversos âmbitos.

Os pressupostos da intervenção podem ser resumidos em duas ações fundamentais, executadas pelos adultos: mediação e intervenção. A mediação da ação de jogar é realizada com o objetivo 
de estimular a tomada de consciência e promover o processo de autorregulação ou equilibração. Com isso, é possível contribuir para as crianças manifestarem suas dificuldades e superarem aquilo que é possível, de acordo com suas condições e/ou limitações. A intervenção focaliza procedimentos insuficientes e atitudes inadequadas, buscando melhorar sua qualidade e eficácia para lidar com os desafios.

Os processos ocorridos no âmbito das intervenções ao jogar, tanto em termos de tomada de consciência, como de autorregulações e construção de novos patamares de equilíbrio favorecem muitos "ganhos" para as crianças. Isto significa, do ponto de vista prático, que há um aumento visível da capacidade de agir com mais autonomia para tomar decisões, corrigir erros e mudar o que está prejudicando os resultados. Além disso, em função das demandas intrínsecas a alguns jogos, as crianças aprendem a cooperar e desenvolvem a noção de respeito mútuo, submetendo-se a regras e organizando suas ações sociais. Outro aspecto relevante decorrente do trabalho com jogos refere-se ao modo como lidam com as dificuldades. Estas passam a ser objeto de observação com possibilidade de mudança, implicando ações coordenadas entre meios e fins, assim como estratégias planejadas. Em termos de procedimentos, pode-se salientar a ocorrência de novas construções para o enfrentamento das situações-problema, de modo mais criativo e elaborado. Ocorre que são transformadas de algo impossível a ser alcançado, para desafio a ser solucionado (no início, com muita ajuda e, posteriormente, com menos necessidade de presença do adulto).

Estas conquistas são gradualmente realizadas pelas crianças, cada uma no seu tempo e condição. O benefício é gerado primeiro no contexto das oficinas; contudo, tem um efeito multiplicado para outros âmbitos, principalmente o escolar, além de se ampliar para a vida de modo mais amplo. Todo este processo não é espontâneo, no sentido de a criança conseguir realizá-lo por si mesma, mas é fruto de mediações e intervenções variadas.

\section{Método}

Os jogos utilizados. Para esse terceiro semestre foram selecionados jogos de comunicação (Imagem e Ação, Qual é a Mensagem e Conte um Conto) e desafios no papel (Cruzadinhas, Caça-Palavras, Stop, dentre outros). É importante ressaltar que estes foram especialmente desafiantes para os sujeitos com dificuldades relacionadas ao processo de alfabetização, pois, além de acionarem o raciocínio lógico, exigiram competências e habilidades linguísticas, bem como domínio de estratégias de interpretação e compreensão. Apesar desta demanda especifica, todos os jogos eram adequados ao público, tendo mesmo sido oferecidas alternativas ao modo de jogar para aqueles que necessitaram, tais como participação oral (e não por escrito) e acompanhamento por um adulto nos momentos em que era solicitado escrever alguma narrativa.

Participantes. Os dados da presente investigação referem-se às informações de nove crianças dos grupos de intervenção com jogos do laboratório. Cumpre destacar que uma delas (o sujeito 2), cujos registros foram analisados anteriormente, não pôde continuar no programa por motivos particulares. Todas estudavam na rede pública, frequentando $3^{\circ}, 4^{\circ}$ ou $5^{\circ}$ anos do ensino fundamental e tendoentre 9 e 11 anos de idade. Além disso, tinham em comum o fato de apresentarem dificuldades escolares relativas a aprendizagem, falta de atenção e comportamentos inadequados, como: agitação, desorganização e agressividade, ou seja, problemas de ordem individual e grupal.

Instrumentos e procedimentos para a coleta e análise de dados. Para a coleta de dados foram utilizados dois protocolos: "registro de observação do jogar" e "registro de observação de ati- 
tudes", já descritos em De Souza et al. (2018) e Petty et al.(submetido), estando brevemente apresentados a seguir.

1 - Registro de observação do jogar. Ações e procedimentos foram registrados cinco vezes durante o semestre e se referiram a quatro momentos: (1) apresentação da situação de jogo; (2) realização do jogo; (3) diante de uma situação de conflito (cognitivo ou social); e (4) avaliação das ações do resultado ao jogar. Para cada momento foram enfatizados três observáveis: interesse, autonomia e um terceiro (sobre funções executivas), diretamente relacionado ao foco de cada um, respectivamente: (1) controle de impulsividade; (2) procedimentos de estratégias; (3) estratégias de superação; e (4) disposição para avaliar. Como critério de registro, pontuaram-se os observáveis de cada momento com escores entre 0 e 4 , sendo $0=$ nenhum; 1=pouco; 2=médio; 3=muito; 4=total.Para o objetivo do presente estudo, que focaliza o terceiro semestre do programa de intervenções, a análise das informações foi feita sobre os observáveis relativos às funções executivas, dando sequência aos estudos sobre os semestres anteriores (vide Anexo 1).

2 - Registro de observação de atitudes. Aspectos atitudinais foram registrados quanto a quatro dimensões: tempo, espaço, objetos e convivência (consigo e com os outros). Este protocolo foi preenchido em duas ocasiões ao longo do semestre: logo no começo dos atendimentos e bem ao final, permitindo confirmar as impressões inicialmente registradas. Cada item do protocolo foi pontuado com escores de 1 a 3 , sendo: $1=$ baixa qualidade, raramente; $2=q u a l i d a d e$ parcial, às vezes; $3=$ alta qualidade, muitas vezes. Para a análise global dos resultados, foram consideradas as relações entre os escores referentes ao jogar e as dimensões atitudinais de tempo e convivências, criança a criança e no conjunto, em função de estabilizações e oscilações. Com isso, foi possível ter uma visão mais integrada das crianças neste último semestre (vide Anexo 2).

\section{Resultados e discussão}

Em De Souza et al. (2018) e Petty, Kunsch e De Souza (submetido) foram apresentados os objetivos de cada momento do jogar, em termos do que as crianças deveriam fazer. 0 momento 1 , de apresentação da situação de jogo, requeria controle de impulsividade, ou seja, que as crianças pudessem agir com autocontrole, prestar atenção, ouvir e permanecer em silêncio durante as explicações. $\mathrm{O}$ momento 2 , relativo à realização do jogo, exigia construção de procedimentos de estratégia, tais como: coordenar regras e ações, aprender novos procedimentos, mudar e criar alternativas para jogar. Já o momento 3 , cujos registros indicavam como a criança atuava em uma situação de conflito (cognitivo ou social), apresentava como demanda fazer uso de recursos como: ser paciente e persistente, buscar alternativas e pedir ajuda diante de um problema, ou seja, construir estratégias de superação para solucionar os erros e enfrentar o que não deu certo. Por fim, o momento 4 exigia a avaliação do resultado das ações ao jogar, isto é, disposição para avaliar, em que a criança expressava compreensão sobre a importância do diálogo e da comunicação de ideias, com vistas a ampliar seu autoconhecimento.

O fato de as crianças já terem frequentado dois semestres (tendo sido desafiadas a participar de diferentes dinâmicas e buscar soluções para atividades com estruturas de jogos variadas) tende a gerar uma maior predisposição para agir com mais autonomia e cooperação. Em outras palavras, o processo de tomada de consciência teria ampliado a percepção das potencialidades, bem como possibilitado novas autorregulações, favorecendo a concentração e atitudes mais cooperativas. Cumpre destacar, assim, que uma maior estabilização nas oscilações em escores superiores era esperada, no sentido de indicar mudança para um novo patamar de equilíbrio. Isto significa que, não se tratando mais nem do primeiro, nem do segundo semestres de intervenções, 
uma consolidação de melhoras deveria ocorrer. No que se refere ao jogar, isto se expressaria principalmente em termos da capacidade de avaliar o desempenho e, no âmbito das atitudes, em particular, nos quesitos relativos às convivências.

Os resultados estão apresentados em Figuras e Quadros quanto aos escores obtidos em todos os registros realizados, tanto para o jogar como para as dimensões atitudinais. Nestes, será possível observar criança a criança e o conjunto das tendências observadas.

OBSERVAÇÃO: como houve desistência por parte do sujeito 2, para a análise aqui apresentada, este foi excluído. No entanto, a numeração original foi mantida, para que se possa comparar com as análises dos outros semestres.

\section{Sujeito 1}

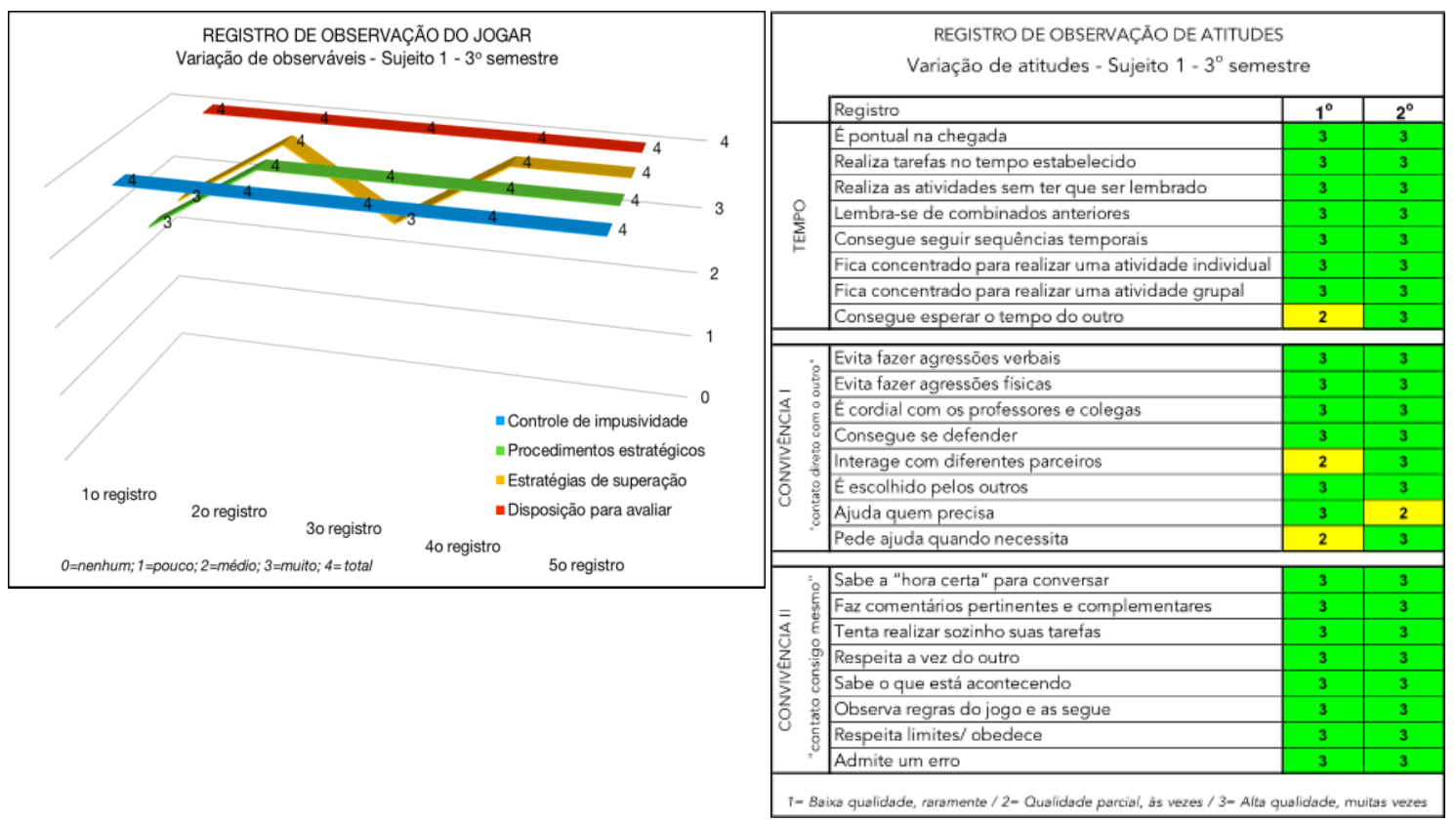

Figura1 e Quadro 1. Dados relativos ao sujeito 1 quanto ao jogar e às atitudes.

A Figura 1 indica, ao mesmo tempo, progressos e consolidação, sendo os dois últimos registros estáveis, com finalização do semestre apresentando exclusivamente escores 4 . Com relação aos observáveis atitudinais, o sujeito 1 iniciou e encerrou o semestre com altíssima qualidade, tanto na dimensão tempo como nas convivências I e II. Seus escores foram predominantemente 3, o que indica ter se beneficiado do programa de intervenção, estando apto a ter alta. Pode-se inferir que há perspectiva de enfrentar desafios com excelente condição de superar as dificuldades que o levaram ao atendimento. 


\section{Sujeito 3}

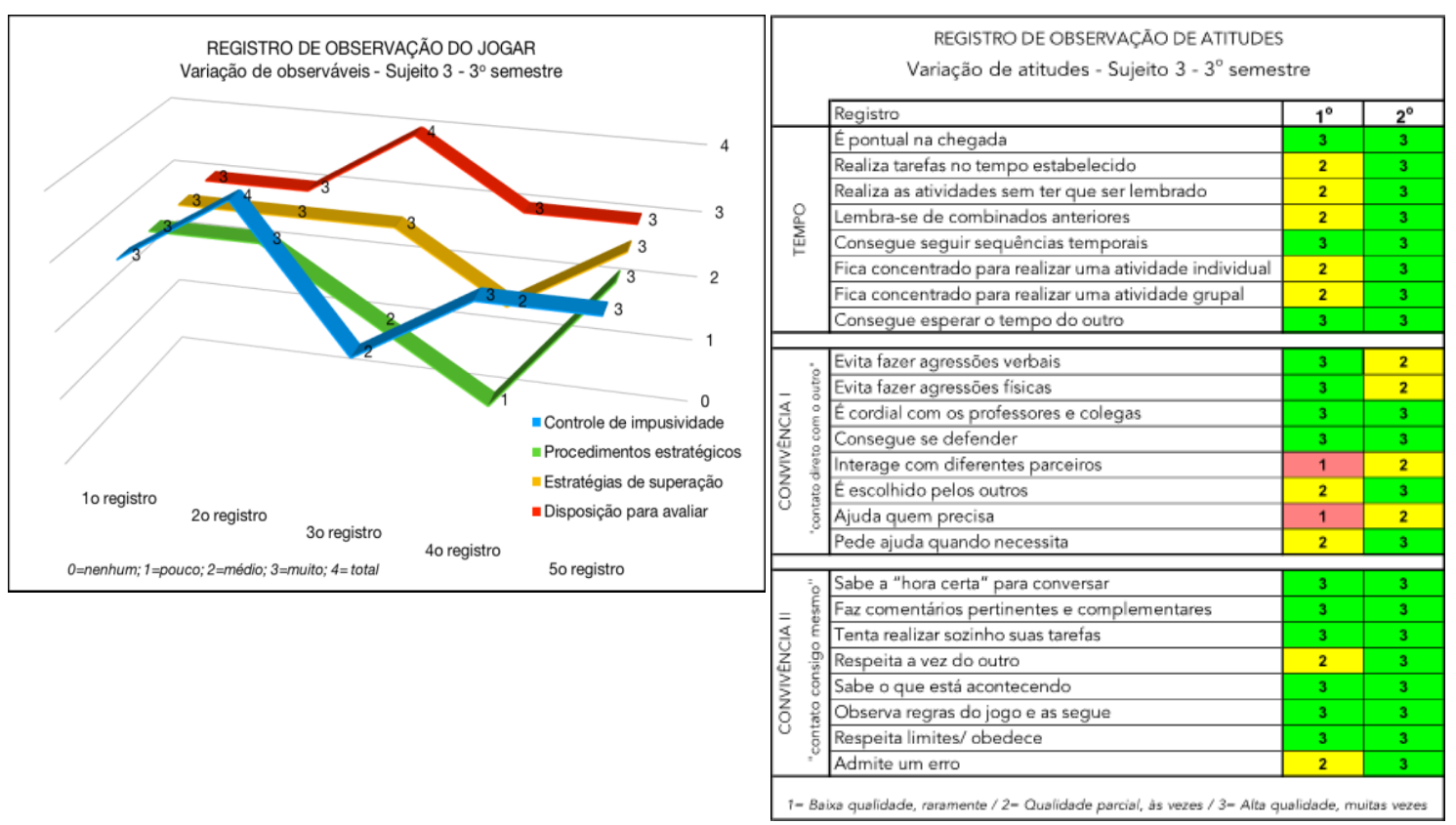

Figura 2 e Quadro 2. Dados relativos ao sujeito 3 quanto ao jogar e às atitudes.

A Figura 2 apresenta várias oscilações, indicando que os jogos utilizados nesse terceiro semestre geraram alguma desestabilização no sujeito 3 , uma vez que demandavam aspectos linguísticos. Com isso, houve situações em que os indicadores referentes a estratégias e controle de impulsividade sofreram queda. No entanto, esse sujeito demonstrou boa capacidade de recuperação, encerrando o semestre com escore 3 em todos os quesitos (cf. Quadro 2). Quanto à dimensão temporal, observa-se que progrediu nos cinco quesitos em queisto era possível, atingindo a totalidade de escores 3 ao final do semestre. Em relação às convivências, apresentou predomínio de melhora, principalmente em convivência II, tendo somente duas quedas emconvivência I nos quesitos relativos a agressões. Pode-se concluir que esse sujeito encontra-se preparado para ter alta, com boas condições de superar diversos desafios, somente tendo que ser orientado quanto ao comportamento em termos do contato com o outro. 


\section{Sujeito 4}

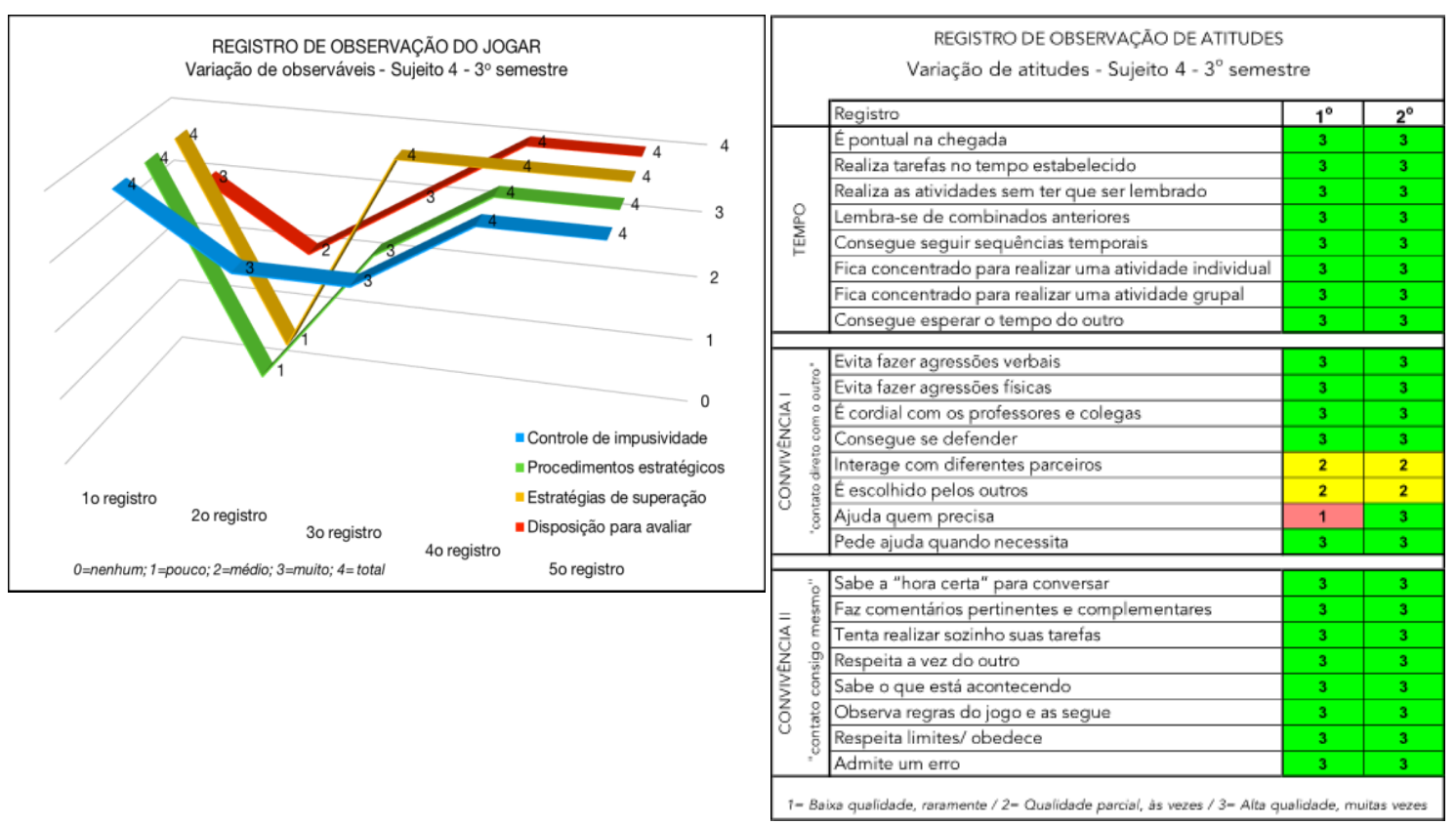

Figura 3 e Quadro 3. Dados relativos ao sujeito 4 quanto ao jogar e às atitudes.

No que se refere à Figura 3, observa-se um processo bastante intenso de recuperação desse sujeito. Começou com escores 4 , caiu para escore 1 nos dois aspectos referentes a estratégias e conseguiu finalizar o semestre com totalidade de escores 4 . Certamente os jogos representaram um grande desafio e as intervenções Ihe serviram de estímulo para superação. Observando-se o Quadro 3, é possível notar que em tempo e convivência llele apresentou estabilidade em escore 3 , indicando alta qualidade de desempenho ao longo do semestre. Seu desafio localiza-se em convivência I no que tange ao contato com o outro. Sendo um tanto tímido, conseguiu se superar e passou a ajudar os colegas quando solicitavam (mudando de escore 1 para 3 ), mas ainda permaneceu com escore 2 nas interações e na escolha de parceiros. Pode-se supor que este foi o seu melhor, já que conseguiu se estabilizar, não tendo obtido escore 1. Esse sujeito finalizou o terceiro semestre com ótimas condições de alta. 


\section{Sujeito 5}

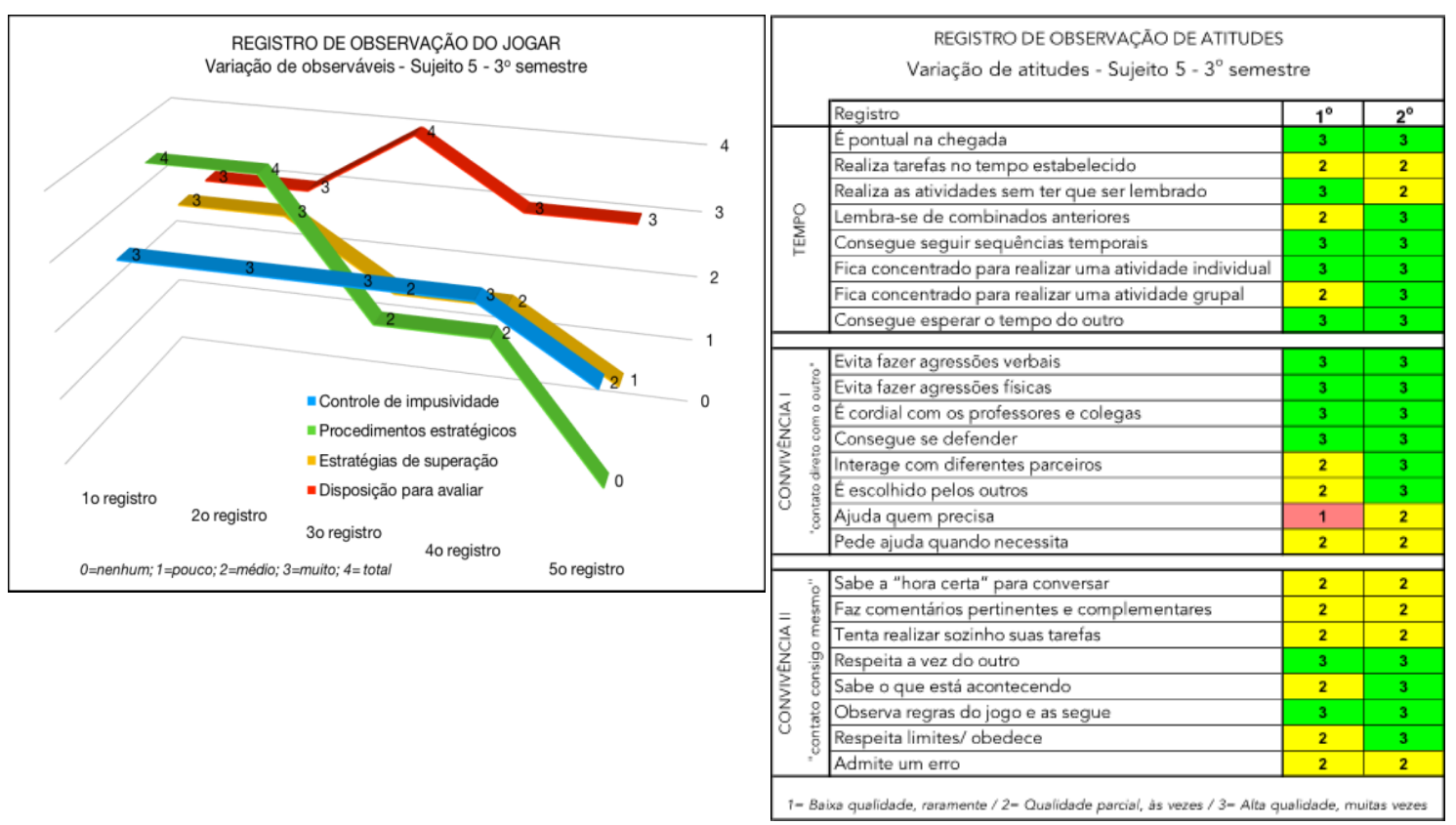

Figura 4 e Quadro 4. Dados relativos ao sujeito 5 quanto ao jogar e às atitudes.

A Figura 4 apresenta o percurso de um sujeito que teve bastante dificuldade nas situações relativas ao contexto do jogar. Começou bem o semestre, com escores 3 e 4, mas houve queda em três observáveis, sem conseguir melhorar. Cumpre destacar que esse sujeito estava em processo de alfabetização e os jogos eram bem desafiantes para ele. No entanto, demonstrou alta disposição para avaliar (escores 3 e 4), indicando que o processo de tomada de consciência está ativo, o que poderá gerar novas autorregulações para superar tais dificuldades. Observando-se o Quadro 4, é possível notar que em termos temporais ele apresentou melhoras quanto à memória e concentração. Somente decaiu de escore 3 para $2 \mathrm{em}$ um quesito (realizar atividades sem ter que ser lembrado), mas este tem mais relação com autonomia do que com memória. De acordo com os registros, suas maiores conquistas estão em convivência I, em que apresentou três melhoras. Em convivência II, necessita ampliar a percepção de si próprio, o que sugere que se beneficiariapermanecendo em atendimento por mais um semestre. 


\section{Sujeito 6}

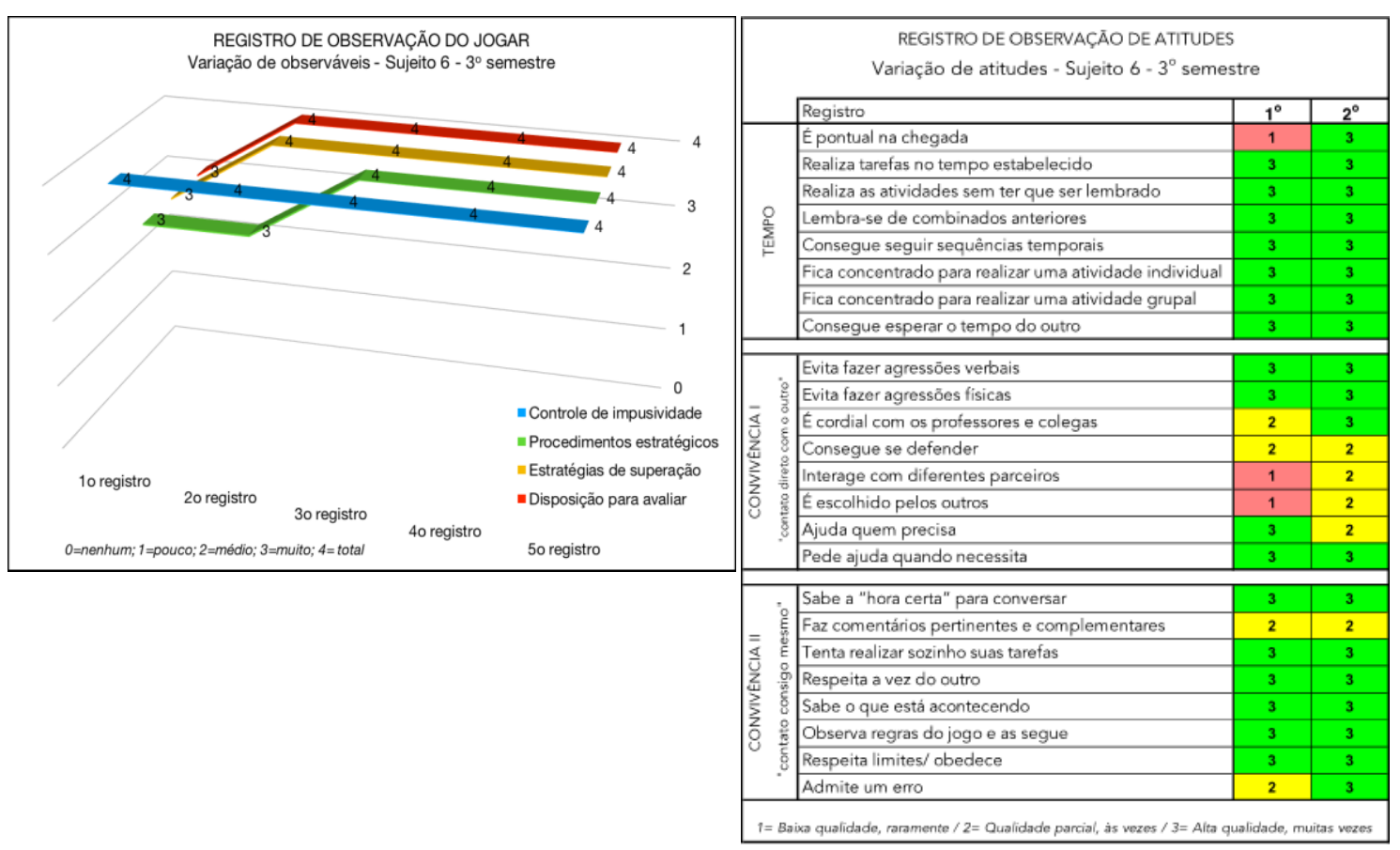

Figura 5 e Quadro 5. Dados relativos ao sujeito 6 quanto ao jogar e às atitudes.

A Figura 5 demonstra que o sujeito iniciou o semestre com predominio de escore 3 , conseguindo atingir escore 4 em todos os observáveis e assim permanecendo até o fim do semestre. Em relação às questões atitudinais (Quadro 5), nota-se que convivência I é o maior desafio para este sujeito. Apesar de ter havido apenas uma piora, em ajuda quem precisa, é onde se destaca a dificuldade que ele apresenta em interagir com as outras crianças. Observa-se que, em convivência II, o único escore 2 , no fim do semestre, está relacionado à qualidade de sua interação. É uma criança apta a ter alta do programa de intervenção, tendo atingido resultados bastante favoráveis. 


\section{Sujeito 7}

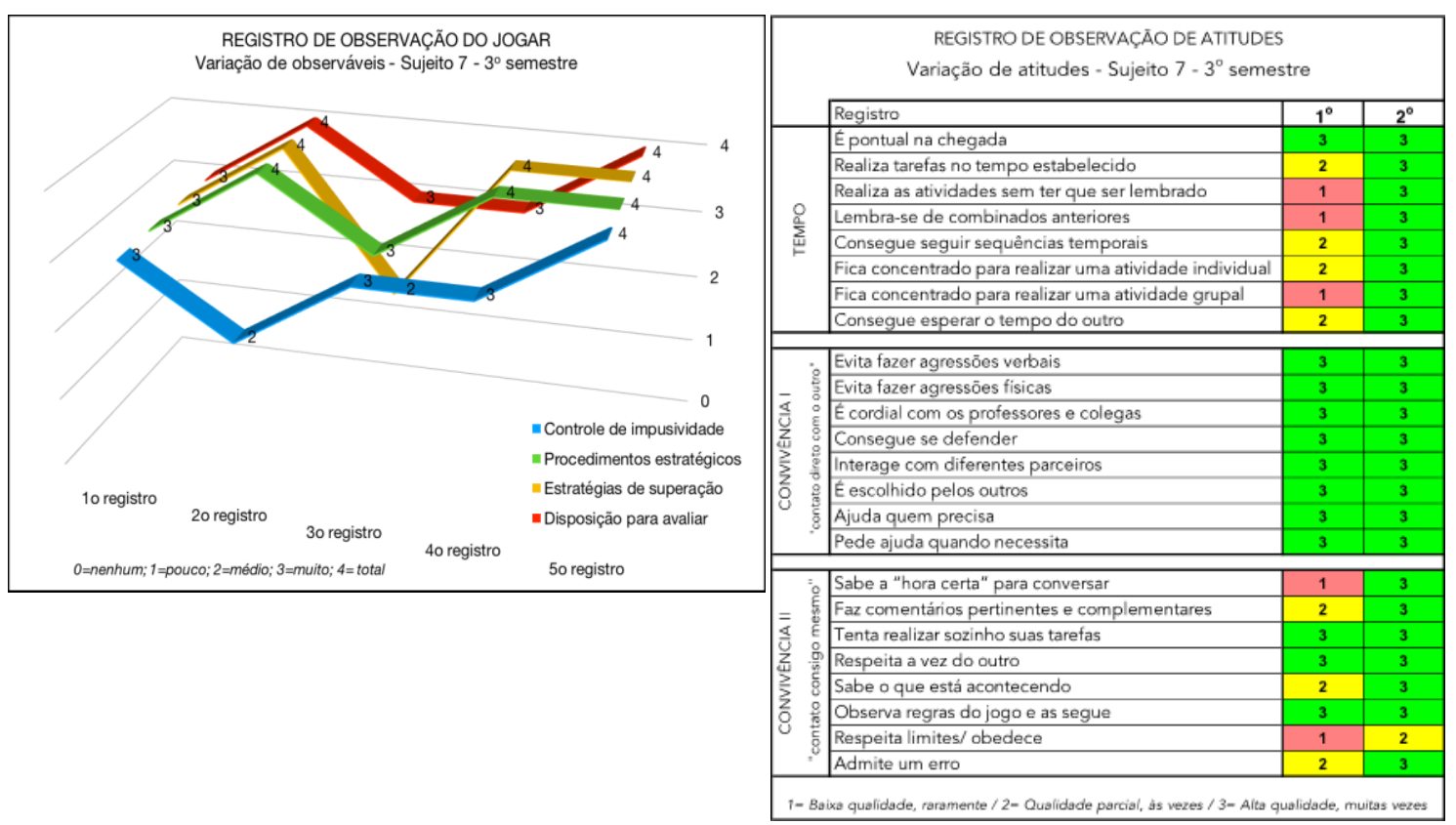

Figura 6 e Quadro 6. Dados relativos ao sujeito 7 quanto ao jogar e às atitudes.

O sujeito 7 apresentou oscilações no decorrer do semestre, conforme mostra a Figura 6. Porém, com predomínio nos escores mais altos (entre 3 e 4) e apenas duas ocorrências de escore 2 (em controle de impulsividade e em estratégias de superação). Conseguiu finalizar o semestre exclusivamente com escore 4, o que demonstra bom desempenho no jogar. Em relação aos aspectos atitudinais (cf. Quadro 6), notam-se progressos em todos os quesitos. A dimensão temporal, que era onde estavam as maiores dificuldades deste sujeito, foi a sua maior conquista, tendo conseguido atingir escore 3 em sua totalidade. Em convivência II, notam-se também progressos no que diz respeito a estar conectado com as propostas, tanto em conteúdo como em saber se expora adequadamente. Este semestre foi muito importante para a finalização da participação desse sujeito no programa de intervenção, tendo tido resultados ótimos para a alta. 


\section{Sujeito 8}

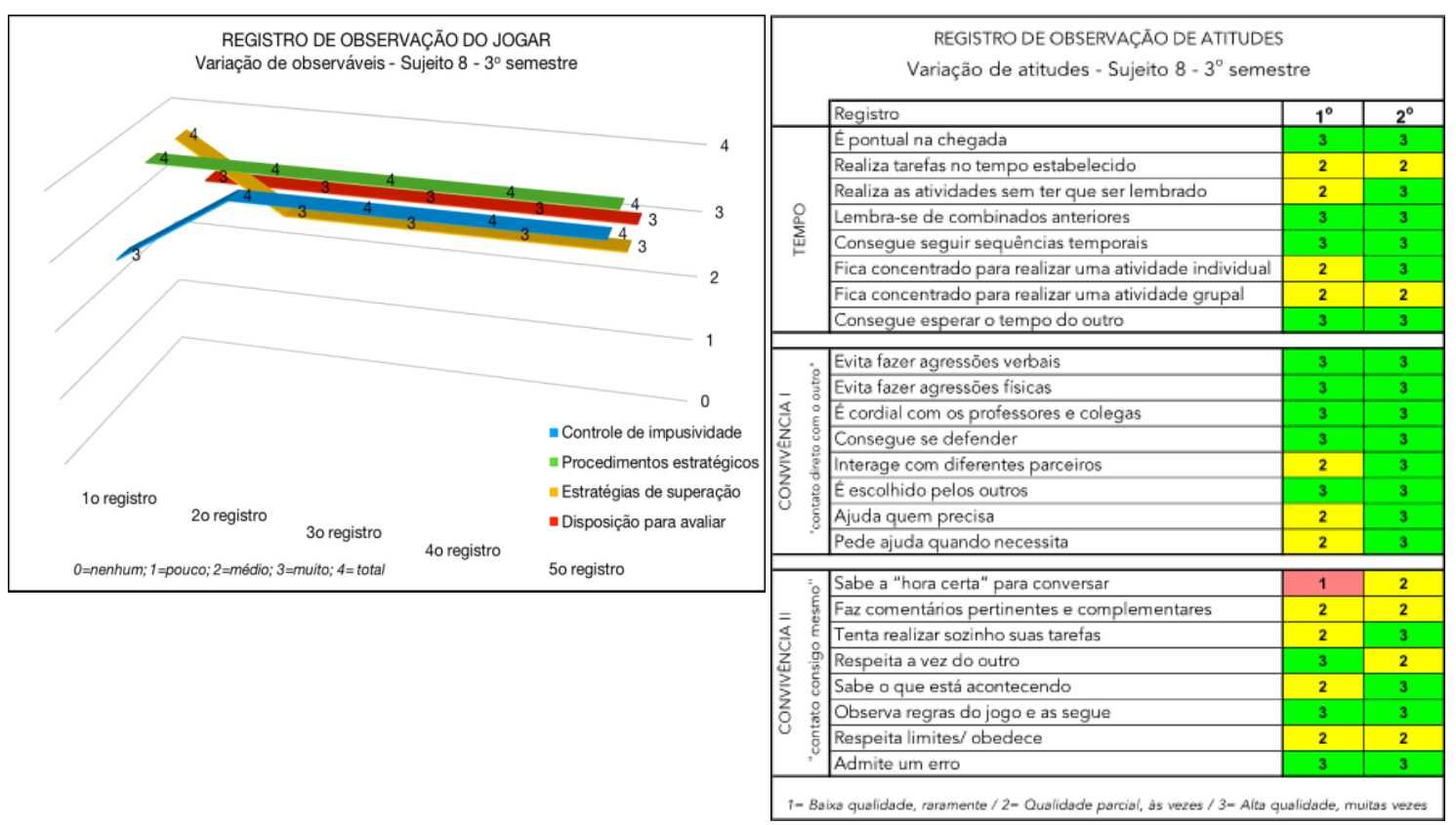

Figura 7 e Quadro 7. Dados relativos ao sujeito 8 quanto ao jogar e às atitudes.

A Figura 7 apresenta estabilidade nos escores 3 e 4, o que indica bom desempenho no jogar. Apesar de os jogos terem sido desafiantes para este sujeito, pois ainda estava na consolidação do processo de alfabetização, ele conseguiu superar desafios. Em relação às atitudes, conforme o Quadro 7, ao final do semestre, nota-se predomínio de melhoras e de escore 3. Na dimensão tempo, apresentou duas melhoras relacionadas a como se organiza e participa das atividades. Manteve-se no escore $2 \mathrm{em}$ tempo de trabalho e concentração em atividades grupais. Em convivência I, apresentou progressos e atingiu escore 3 na totalidade. Já em convivência II, obteve três melhoras, manteve-se estável em quatro quesitos, e apresentou também a sua única piora nas questões atitudinais, em respeita a vez do outro. $O$ grande desafio para o sujeito 8 é conseguir respeitar limites e participar de maneira produtiva e pertinente. Por estes motivos, sugeriu-se a continuação nas oficinas por mais um semestre. 


\section{Sujeito 9}

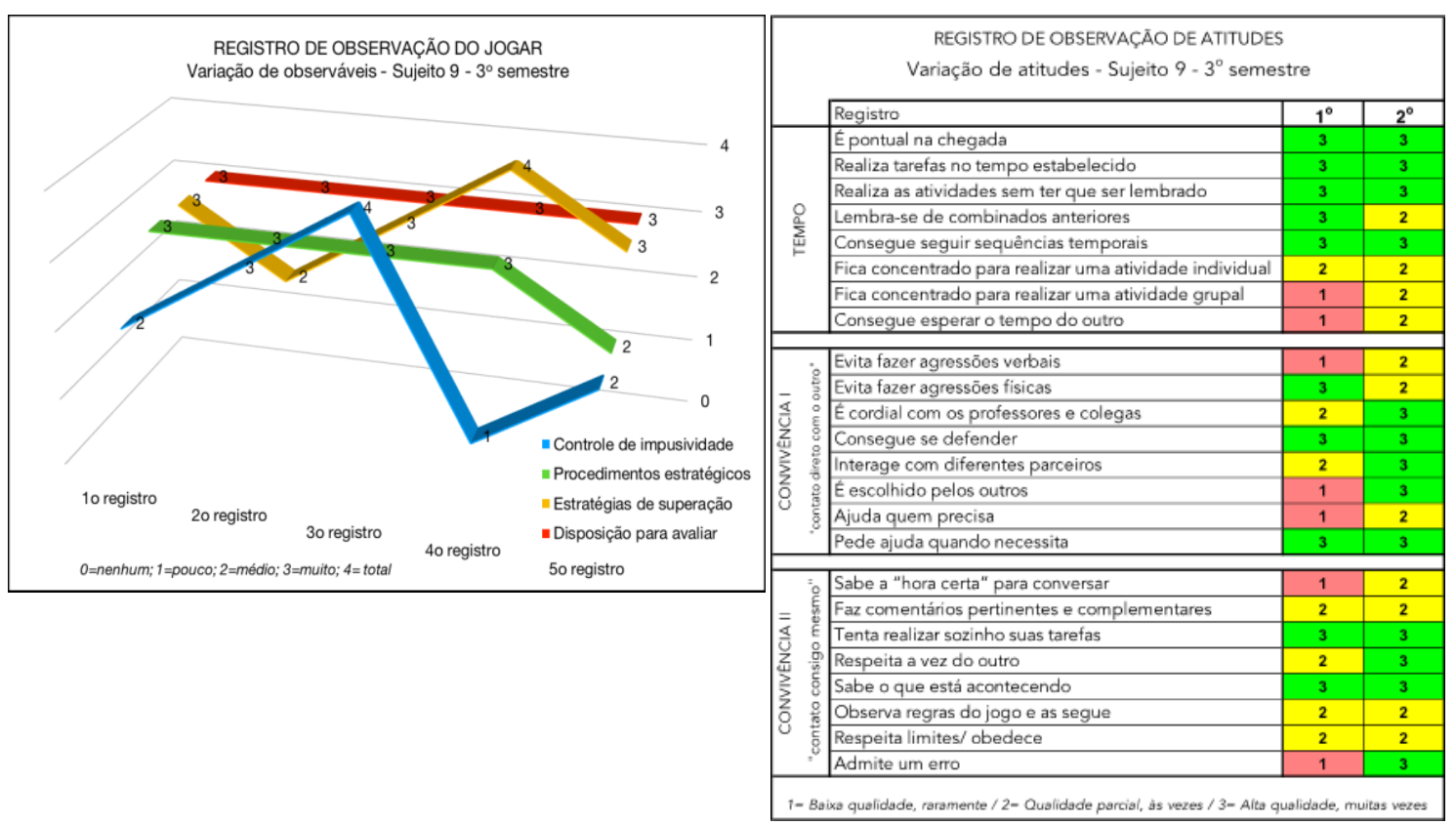

Figura 8 e Quadro 8. Dados relativos ao sujeito 9 quanto ao jogar e às atitudes.

No que se refere à Figura 8, observa-se um sujeito com procedimentos oscilantes, em três quesitos relativos ao jogar. Como ainda não tinha bom domínio em termos de alfabetização, apresentou algumas diminuições de escore no decorrer do semestre. No entanto, houve permanente disposição para avaliar, o que permite concluir que poderá superar suas dificuldades, por estar atento aos procedimentos insuficientes. 0 Quadro 8 , por sua vez, indica que ainda apresenta questões atitudinais. No entanto, é possível constatar progressos, pois no início do semestre havia ocorrência de vários escores $1 \mathrm{e}$, ao final, todos foram superados, passando para escores 2 ou até mesmo 3 . Na dimensão tempo, destacam-se mudanças de escore 1 para 2 nos quesitos relativos à concentração; em convivência I, a relação com os colegas foi ampliada, com cinco quesitos apresentando progresso. Em convivência II, melhorou a relação com os colegas, indicando ser este aspecto sua principal resposta às intervenções. Assim sendo, apresentou boas condições de alta. 


\section{Sujeito 10}

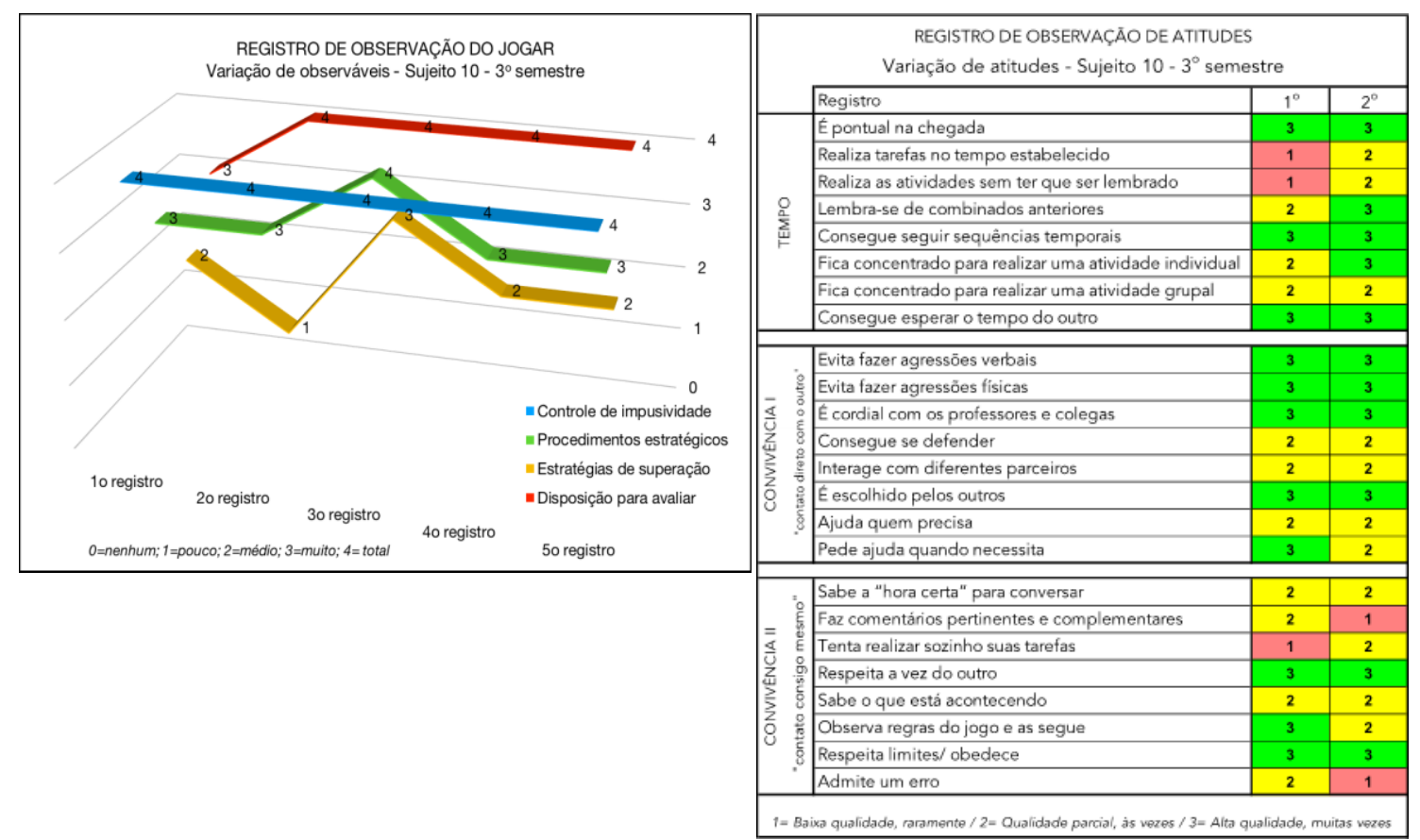

Figura 9 e Quadro 9. Dados relativos ao sujeito 10 quanto ao jogar e às atitudes.

O sujeito 10 apresentou oscilações em procedimentos de estratégias, iniciando com escore 3 , subindo para 4 e novamente caindo para 3. Em estratégias de superação, registrou escores baixos (2 e 1), no início, subindo para 3, mas novamente caindo para 2, ao final do semestre, conforme mostra a Figura 9. Os jogos utilizados foram um grande desafio, uma vez que ele demonstra bastante dificuldade no processo de alfabetização e na utilização de estratégias de comunicação. 0 Quadro 9 apresenta melhoras em tempo, predomínio de estagnação em convivência I, e três pioras em convivência II, exibindo dois escores 1 . Nota-se que os quesitos atitudinais relacionados a como lidar com conflitos (cognitivos e sociais) são aqueles em que o sujeito não conseguiu ter bom desempenho. Neste caso, sugere-se a continuidade dos atendimentos por mais um semestre.

Em síntese, ao serem analisadas as Figuras de 1 a 9, buscou-se observar se houve consolidação no jogar, ou seja, se as crianças conseguiram manter os patamares já conquistados, apresentando escores 3 e 4 para todos os observáveis. Como já mencionado, os jogos trabalhados nesse semestre foram particularmente desafiantes para as crianças com dificuldades em alfabetização e, assim, poderiam ocorrer oscilações, tal como salientado nas análises individuais. Nesse âmbito, os escores em disposição para avaliar foram especialmente considerados. $\mathrm{O}$ objetivo foi verificar se, para aqueles sujeitos com mais oscilações, a alta disponibilidade para avaliar compensou os escores baixos em estratégias. Isto em virtude da expectativa de que o processo de tomada de consciência e a ampliação da autonomia gerariam uma mobilização em prol de saber o motivo de não terem jogado bem.

De modo geral, notou-se que, em todos os observáveis do jogar, dentre as nove crianças, seis (sujeitos 1, 3, 4, 6, 7 e 8) apresentaram somente escores 3 ou 4 no final do semestre e as demais (sujeitos 5, 9 e 10) não obtiveram predomínio destes escores no último registro. Nota-se que a maneira como cada criança enfrentou os desafios variou: (a) todos os sujeitos se mantiveram com escores 3 ou 4 quanto à disposição para avaliar; (b) os sujeitos 1, 6 e 8 apresentaram predominio de estabilidade; (c) os sujeitos 3, 4 e 7 apresentaram oscilações, mas conseguiram superar os baixos 
escores e finalizar com escores 3 ou 4; e (d) os registros dos sujeitos 5, 9 e 10 indicaram que apesar das intervenções, ainda assim não foi possível atingir escores altos no final do semestre. Nestes casos, foi sugerida a possibilidade de permanência no programa por mais um semestre.

No que se refere aos Quadros de 1 a 9, para todos os sujeitos a dimensão tempo apresentou escores que expressam consolidação das conquistas iniciadas no segundo semestre, uma vez que há predomínio de estabilização em escores altos e/ou melhora na maioria dos quesitos.

Quanto à dimensão convivências, observou-se que houve um predomínio de estabilização dos escores ao longo do semestre, para maioria dos sujeitos. Outro aspecto que interessa ser ressaltado é que não há pioras (exceção para o sujeito 10, que será comentada adiante). Os destaques em convivência I concentram-se nos sujeitos 3 e 9, que apresentaram melhora em quase todos os quesitos. Já os sujeitos 1 , 4, 5, 6, 7, 8 e 10 estabilizaram em escores obtidos no início do semestre, sendo que há maioria de escores 3 no final. Em convivência II, os sujeitos 7, 8 e 9 obtiveram escores superiores aos iniciais em quase todos os registros. Além disso, houve estabilização com predominio de escores 3 para os sujeitos 1, 3, 4, 5 e 6. Como já mencionado, somente o sujeito 10 apresentou três pioras e quatro estabilizações em escore 2 , o que indica necessidade de continuar recebendo apoio para suas dificuldades.

\section{Considerações finais}

As análises relativas ao terceiro semestre do programa de intervenção mostraram uma série de aspectos interessantes a serem apontados. Os resultados indicaram que o processo de tomada de consciência sofreu constante ampliação, assim como houve construção de novas regulações diante das perturbações trazidas pelas situações-problema. Tais conquistas geraram melhoras visíveis, tanto nas ações e nosprocedimentos de jogar, como nas atitudes manifestadas que constavam nos registros. Foi possível notar que as crianças apresentaram maior concentração para realizar as propostas, bem como estiveram mais predispostas para atuar com respeito mútuo e cooperação em relação ao outro. Além disso, evoluíram em autonomia, principalmente percebendo quando seria necessário pedir ajuda ao adulto, identificando as atividades que eram capazes de realizar por si mesmas. Tais atitudes confirmam a hipótese de que o processo de tomada de consciência, iniciado em semestres anteriores, permaneceu ativo e se ampliou no período. Por esse motivo, a maioria dos participantes pôde receber alta com boas condições de enfrentar os desafios escolares, isto é, tornaram-se mais atentos e cientes de seus recursos para lidar com as situações de aprendizagem e com suas dificuldades. E mesmo aqueles que ainda precisariam de acompanhamento por mais um período, apresentaram indicadores que demonstraram estar fortalecidos e determinados para continuar tentando realizar mudanças, principalmente ao manifestarem disposição para avaliar suas ações e atitudes.

No âmbito do programa como um todo, pode-se destacar a ampliação do conhecimento sobre as diferentes formas de intervenção que se mostraram eficazes para promover mudanças favoráveis ao desenvolvimento e à aprendizagem dos participantes. Atividades que focalizam a comunicação, construção de estratégias e resolução de problemas, com desafios lógicos e/ou sociais, definitivamente trazem os estímulos necessários, conforme os resultados apresentados. Isto significa afirmar que os jogos e as situações-problema previamente selecionados para cada semestre estão de acordo com a pluralidade das necessidades dos participantes. Por esta razão, primeiramente é possível desencadear manifestações de desequilíbrio, com muitas oscilações, propondo-se jogar em contextos e dinâmicas bem variadas. Em seguida, por meio de questionamentos e pedidos de explicação das ações, dá-se início a um processo em que, cada criança, no seu tempo e nas suas condições, começa a perceber a incompletude dos recursos até então empregados para realizar as tarefas. Tais intervenções geram reações importantes, provocando 
alterações no potencial individual, uma vez que ocorre a ampliação do uso de novas ferramentas cognitivas (ou de competências e habilidades que não estavam sendo usadas). Com isso, contribui-se para a construção de procedimentos mais consistentes, que culminam na transição para um novo patamar. Por fim, várias ações e atitudes são reequilibradas e se consolidam, graças a intervenções de caráter mediador, ou seja, mais voltadas para a autoobservação e avaliação dos resultados analisados pela própria criança, ainda que com suporte do adulto.

Em síntese, os benefícios de participar do programa de intervenção com jogos são pelo menos cinco: (1) favorecer o desenvolvimento de ações mais focadas para alcançar um objetivo; (2) instigar as crianças com dificuldades escolares a melhorar a capacidade de enfrentar desafios; (3) promover mudanças positivas no uso/emprego das funções executivas; (4) gerar necessidade de se estabelecer ritmo de trabalho compatível com as demandas; e (5) possibilitar a percepção da importância da cooperação e socialização.

Por fim, exclusivamente a título de complemento, podem ser mencionadas informações por parte dos responsáveis pelas crianças de que, ao longo da participação no programa, ocorre redução de muitas atitudes inadequadas que se manifestavam no cotidiano de seus lares. Aspectos relativos à organização das tarefas escolares e autonomia, bem como convivência com pais e irmãos apresentam importantes mudanças. Com isso, reconfirma-se o valor de seguir com este programa de intervenção com jogos, oferecendo a mais crianças a oportunidade de se tornarem protagonistas de muitas transformações!

\section{Referências}

CYPEL, S. Déficit de atenção e hiperatividade e as funções executivas: atualização para pais, professores e profissionais de saúde. São Paulo: Editorial Lemos, 2007.

DE SOUZA, M. T. C. C. PETTY, A. L.; KUNSCH, C. \& SANTOS, R. J. Desafiando crianças a pensar: intervenção com jogos. Revista Construção Psicopedagógica, 26 (27): 53-69, 2018

DE SOUZA, M. T. C. C. \& PETTY, A. L. Communicative development in a game context. Psychology, 8, 246-257, 2017.

DE SOUZA, M. T. C. C. PETTY, A. L., FOlQUitTo, C. T., GARBARINO, M. \& MONTEIRO, T. A. Does playing games contribute to develop better attitudes? Psychology Research. 4 (4), 301-309, 2014.

DE SOUZA, M. T. C. C., PETTY, A. L., DE CARVAlHO, G. E., PASSOS, N. C. \& CARRACEDO, V. Assessing game activities: a study with Brazilian children. IN: J. Retschitzki \& R. Haddad-Zubel (orgs). Step by step. Éditions Universitaires: Fribourg, Suisse, 2002.

DIAMOND, A. Executive functions. Annual Review Psychology, 64, 135-168, 2013.

FOLQUITTO, C. T. Desenvolvimento psicológico e estratégias de intervenção em crianças com transtorno de déficit de atenção e hiperatividade (TDAH). Tese de Doutorado, Programa de Pós-Graduação em Psicologia Escolar e do Desenvolvimento Humano, Universidade de São Paulo, São Paulo, SP, 2013.

GARBARINO, M. I. Construção do prazer de pensar e desenvolvimento: um estudo teórico-clínico com crianças em dificuldade escolar. Tese de Doutorado, Programa de Pós-Graduação em Psicologia Escolar e do Desenvolvimento Humano, Universidade de São Paulo, São Paulo, SP, 2017. 
MACEDO, L. de PETTY, A. L., DE CARVALHO, G. E. \& DE SOUZA, M. T. C. C. O jogo dominó das 4 cores: estudo sobre análise de protocolos. Psicologia Escolar e Educacional, 18(3), 429-438, 2014.

MACEDO, L. de PETTY, A. L., DE CARVALHO, G. E., \& DE SOUZA, M. T. C. C. Intervenção com jogos: estudo sobre o Tangram. Psicologia Escolar e Educacional, 19 (1), 13-22, 2015.

MACEDO, L. de PETTY, A. L. \& PASSOS, N. C. 4cores, senha e dominó: oficinas de jogos em uma perspectiva construtivista e psicopedagógica. São Paulo: Casa do Psicólogo, 1997.

MACEDO, L. de PETTY, A. L. \& PASSOS, N. C. Aprender com jogos e situações-problema. Porto Alegre: Artmed, 2000.

MACEDO, L. de PETTY, A. L. \& PASSOS, N. C. Os jogos e o lúdico na aprendizagem escolar. Porto Alegre: Artmed, 2005.

PETTY, A. L. \& DE SOUZA, M. T. C. C. Executive functions development and playing games. US-China Education Review B, 9, 795-801, 2012.

PETTY, A. L. \& DE SOUZA, M. T. C. C. Social development in a game context. Psychology, 5, 1419-1425, 2014.

PETTY, A. L., KUNSCH, C. \& DE SOUZA, M. T. C. C. (submetido). Desafiando crianças a pensar: intervenção com jogos e processos de desenvolvimento. Revista Construção Psicopedagógica

PIAGET, J. A equilibração das estruturas cognitivas: problema central do desenvolvimento. Lisboa: Publicações Dom Quixote, 1974.

PIAGET, J. A tomada de consciência. São Paulo: Melhoramentos, 1977.

PIAGET, J. Fazer e compreender. São Paulo: Edusp, 1978.

PIAGET, J. O juízo moral na criança. São Paulo: Summus Editorial, 1994. 


\section{ANEXO 1 - REGISTRO DE OBSERVAÇÃO DO JOGAR}

Critérios para registrar resultado das informações: $0=$ nenhum $1=$ pouco $2=$ médio $3=$ muito $4=$ total

\begin{tabular}{|c|c|c|c|}
\hline \multicolumn{4}{|c|}{1 - Na apresentação da situação de jogo a criança manifestou: } \\
\hline \multirow[t]{4}{*}{ Data } & \multirow[t]{4}{*}{ Atividade } & \multirow[t]{2}{*}{ Pontuação } & \multirow[t]{2}{*}{ Observações } \\
\hline & & & \\
\hline & & Autonomia & \\
\hline & & Controle de Impulsividade & \\
\hline & & Interesse & \\
\hline & & Autonomia & \\
\hline & & Controle de Impulsividade & \\
\hline & & Interesse & \\
\hline & & Autonomia & \\
\hline & & Controle de Impulsividade & \\
\hline & & Interesse & \\
\hline & & Autonomia & \\
\hline & & Controle de Impulsividade & \\
\hline & & Interesse & \\
\hline & & Autonomia & \\
\hline & & Controle de Impulsividade & \\
\hline
\end{tabular}

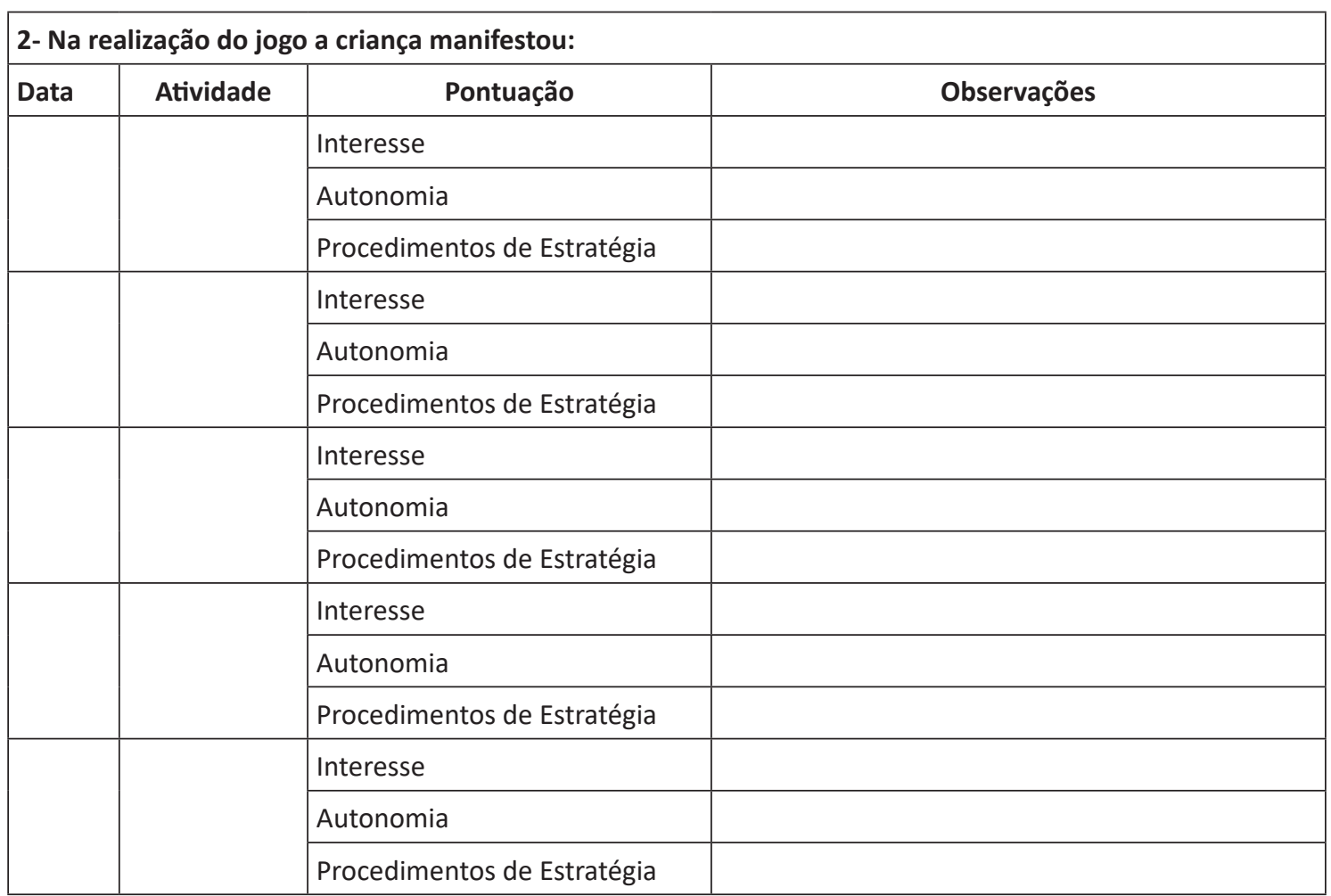




\begin{tabular}{|c|c|c|c|}
\hline \multicolumn{4}{|c|}{3 - Diante de uma situação de conflito (cognitivo ou social) predominou: } \\
\hline Data & Atividade & Pontuação & Observações \\
\hline & & Interesse & \\
\hline & & Autonomia & \\
\hline & & Estratégias de Resolução & \\
\hline & & Interesse & \\
\hline & & Autonomia & \\
\hline & & Estratégias de Resolução & \\
\hline & & Interesse & \\
\hline & & Autonomia & \\
\hline & & Estratégias de Resolução & \\
\hline & & Interesse & \\
\hline & & Autonomia & \\
\hline & & Estratégias de Resolução & \\
\hline & & Interesse & \\
\hline & & Autonomia & \\
\hline & & Estratégias de Resolução & \\
\hline
\end{tabular}

\begin{tabular}{|c|c|c|c|}
\hline \multicolumn{4}{|c|}{4 - Na avaliação do resultado das ações ao jogar a criança demonstrou: } \\
\hline Data & Atividade & Pontuação & Observações \\
\hline & & Interesse & \\
\hline & & Autonomia & \\
\hline & & Disposição p/ Avaliar & \\
\hline & & Interesse & \\
\hline & & Autonomia & \\
\hline & & Disposição p/ Avaliar & \\
\hline & & Interesse & \\
\hline & & Autonomia & \\
\hline & & Disposição p/ Avaliar & \\
\hline & & Interesse & \\
\hline & & Autonomia & \\
\hline & & Disposição p/ Avaliar & \\
\hline & & Interesse & \\
\hline & & Autonomia & \\
\hline & & Disposição p/ Avaliar & \\
\hline
\end{tabular}




\section{CRITÉRIOS PARA ATRIBUIR PONTUAÇÃO EM CADA CATEGORIA}

INTERESSE 0 = Desinteresse. Nenhuma predisposição para a tarefa.

INTERESSE 1 = Baixa conexão com a tarefa. Dispersão.

INTERESSE 2 = Alguma conexão com a tarefa.

INTERESSE 3 = Predisposição para a tarefa com alguma dispersão.

INTERESSE 4 = Total predisposição para a tarefa com envolvimento.

AUTONOMIA 0 = Não autonomia e não iniciativa. $\mathrm{O}$ adulto decide o que fazer

AUTONOMIA 1 = Demora para começar. Muita (+ q 1x) demanda (apoio) do adulto.

AUTONOMIA 2 = Dúvidas sobre como proceder (ações e procedimentos específicos para jogar)

AUTONOMIA 3 = Iniciativa com pouca (no máximo 1x) demanda do adulto.

AUTONOMIA 4 = Iniciativa com tomada de decisão própria.

CONTROLE DE IMPULSIVIDADE 0 = Ação sem aguardar instrução.

CONTROLE DE IMPULSIVIDADE 1 = Ação com pouca consideração da instrução.

CONTROLE DE IMPULSIVIDADE 2 = Ação considerando apenas parte da instrução.

CONTROLE DE IMPULSIVIDADE 3 = Ação imediata considerando a instrução.

CONTROLE DE IMPULSIVIDADE 4 = Ação de jogar refletida (planejada e/ou intencional), após instrução.

PROCED/os DE ESTRATÉGIA 0 = Ação aleatória, com ou sem finalização.

PROCED/os DE ESTRATÉGIA 1 = Ação pouco planejada com certo grau de aleatoriedade.

PROCED/os DE ESTRATÉGIA 2 = Ação que considera as regras recorrendo muito (+ q 1x) ao adulto

PROCED/os DE ESTRATÉGIA 3 = Ação que considera as regras recorrendo pouco (no máximo 1x) ao adulto

PROCED/os DE ESTRATÉGIA 4 = Ação planejada ou bem-sucedida, de acordo com as regras.

ESTRATÉGIAS DE SUPERAÇÃO 0 = Desconsideração do conflito. Ação de desistência.

ESTRATÉGIAS DE SUPERAÇÃO 1 = Consideração do conflito com estratégias aleatórias.

ESTRATÉGIAS DE SUPERAÇÃO 2 = Consideração do conflito com ajuda do adulto. Ação apoiada nesta orientação.

ESTRATÉGIAS DE SUPERAÇÃO 3 = Consideração do conflito se remetendo ao apontamento do adulto. Ação de enfrentamento.

ESTRATÉGIAS DE SUPERAÇÃO 4 = Consideração do conflito. Ação de enfrentamento de um novo modo.

DISPOSIÇÃO PARA AVALIAR 0 = Nenhuma disposição para rever as ações.

DISPOSIÇÃO PARA AVALIAR 1 = Alguma disposição, sem foco nos resultados.

DISPOSIÇÃO PARA AVALIAR 2 = Disposição rever as ações, com muita (+ q 1x) intervenção do adulto.

DISPOSIÇÃO PARA AVALIAR 3 = Disposição para rever as ações, com pouca (no máximo 1x) intervenção do adulto.

DISPOSIÇÃO PARA AVALIAR 4 = Disposição espontânea para rever as ações. 


\section{ANEXO 2 - REGISTRO DE OBSERVAÇÃO DE ATITUDES}

CRITÉRIOS A SEREM CONSIDERADOS: 1 = inexistência, baixa qualidade, raramente ou nunca; 2 = razoável ou às vezes; 3 = alta qualidade, muitas vezes ou sempre

\section{TEMPO}

\begin{tabular}{llll}
\hline É pontual na chegada & 1 & 2 & 3 \\
Realiza tarefas no tempo estabelecido & 1 & 2 & 3 \\
Realiza as atividades sem ter que ser lembrado & 1 & 2 & 3 \\
Lembra-se de combinados anteriores & 1 & 2 & 3 \\
Consegue seguir sequências temporais & 1 & 2 & 3 \\
Fica concentrado para realizar uma atividade individual & 1 & 2 & 3 \\
Fica concentrado para realizar uma atividade grupal & 1 & 2 & 3 \\
Consegue esperar o tempo do outro & 1 & 2 & 3
\end{tabular}

\section{ESPAÇO}

Permanece no lugar

Consegue manter-se na cadeira sem derrubá-la ou cair

Fica na sala durante todo o período

Mantém organizado o local onde está trabalhando

Ocupa o espaço sem interferir no espaço alheio

Organiza-se em diferentes espaços simultaneamente

Utiliza o espaço do papel com harmonia (distribuição dos registros)

Domina o espaço do jogo (tabuleiro, local ocupado, deslocamentos)

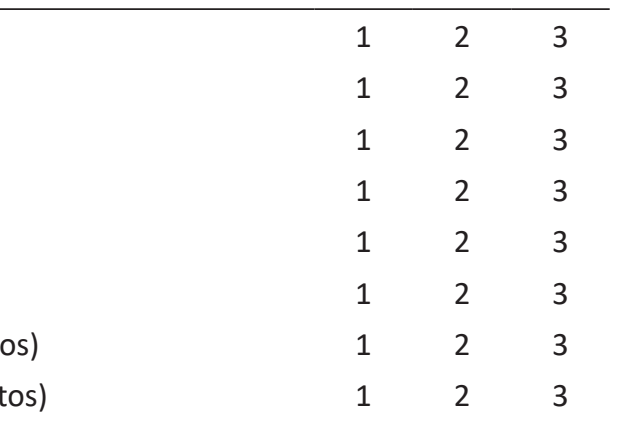

\begin{tabular}{llll}
\hline OBJETOS & & & \\
\hline Mantém objetos consigo (sem jogá-los ou derrubá-los) & 1 & 2 & 3 \\
Preserva os materiais (não estraga nem quebra) & 1 & 2 & 3 \\
Utiliza o papel cuidadosamente (não suja, amassa ou rasga) & 1 & 2 & 3 \\
Guarda corretamente papéis na pasta & 1 & 2 & 3 \\
Ajuda a distribuir materiais & 1 & 2 & 3 \\
Consegue compartilhar materiais com os colegas & 1 & 2 & 3 \\
Sabe encontrar os materiais e guarda nos devidos lugares após o uso & 1 & 2 & 3 \\
Sabe qual é(são) sua(s) peça(s) na partida e o que deve fazer & 1 & 2 & 3
\end{tabular}

\section{CONVIVÊNCIA I ("contato direto com o outro")}

Evita fazer agressões verbais

$\begin{array}{lll}1 & 2 & 3 \\ 1 & 2 & 3 \\ 1 & 2 & 3 \\ 1 & 2 & 3 \\ 1 & 2 & 3 \\ 1 & 2 & 3 \\ 1 & 2 & 3 \\ 1 & 2 & 3\end{array}$

Evita fazer agressões físicas

É cordial com os professores e colegas

Consegue se defender

Interage com diferentes parceiros

É escolhido pelos outros

Ajuda quem precisa

Pede ajuda quando necessita 


\section{CONVIVÊNCIA II ("contato consigo mesmo")}

Sabe a "hora certa" para conversar

Faz comentários pertinentes e complementares

123

Tenta realizar sozinho suas tarefas

123

Respeita a vez do outro

Sabe o que está acontecendo

123

Observa regras do jogo e as segue

Respeita limites/ obedece

123

123

123

123

Admite um erro

123

